\title{
Correction to: Botanical insecticide and natural enemies: a potential combination for pest management against Tuta absoluta
}

\author{
Marianne A. Soares ${ }^{1,2}$ - Mateus R. Campos ${ }^{2} \cdot$ Luis C. Passos $^{1} \cdot$ Geraldo A. Carvalho $^{1} \cdot$ Marcelo M. Haro $^{3}$. \\ Anne-Violette Lavoir ${ }^{2} \cdot$ Antonio Biondi $^{4} \cdot$ Lucia Zappalà $^{4} \cdot$ Nicolas Desneux $^{2}$
}

Published online: 6 March 2019

○) Springer-Verlag GmbH Germany, part of Springer Nature 2019

\section{Correction to: Journal of Pest Science https://doi.org/10.1007/s10340-018-01074-5}

In the original publication of the article, the authors have inadvertently missed to include a statement in the Acknowledgement section and the corrected version is given below.

The authors thank Philippe Bearez, Edwige AmiensDesneux and Christiane Metay-Merrien from INRA for technical assistance and the Coordination of Superior Level Staff Improvement (Capes), Minas Gerais State Foundation for Research (FAPEMIG) and CNPq (National Council for Scientific and Technological Development) for providing funding to MAS (Ph.D. fellowship), the Project EUCLID (H2020-SFS-2014, Grant No. 633999) for funding to ND and the Project STomP (ARIMnet2, Grant Agreement: 618127) for funding to ND, A-VL, AB and LZ. ND and MC were supported by the IPM Innovation Lab (AID-OAA-14-000018).

The original article can be found online at https://doi.org/10.1007/ s10340-018-01074-5.

Marianne A. Soares

marianne_bio@hotmail.com

1 Laboratório de Ecotoxicologia, Departamento de Entomologia, Universidade Federal de Lavras, Lavras, MG CEP 37200-000, Brazil

2 INRA (French National Institute for Agricultural Research), Université Côte d'Azur, CNRS, UMR 1355-7254, Institut Sophia Agrobiotech, 06903 Sophia Antipolis, France

3 Laboratório de Entomologia, Estação Experimental de Itajaí, Empresa de Pesquisa Agropecuária e Extensão Rural de Santa Catarina (Epagri), Florianópolis, Santa Catarina, RS CEP 88034-901, Brazil

4 Department of Agriculture, Food and Environment, University of Catania, Via Santa Sofia 100, 95123 Catania, Italy
Publisher's Note Springer Nature remains neutral with regard to jurisdictional claims in published maps and institutional affiliations. 